Gazi University
Journal of Science
http://dergipark.gov.tr/gujs

\title{
Optimal Reinsurance Minimizing the Absolute Value of the Difference between the Profits of the Insurer and the Reinsurer
}

\author{
Murat BUYUKYAZICI ${ }^{\circ}$, Betul Zehra KARAGUL* \\ Hacettepe University, Department of Actuarial Science,06800, Ankara, Turkey
}

\author{
Highlights \\ - The optimal reinsurance problem from the point of view of both parties. \\ - The absolute value of the difference between the insurer's and the reinsurer's profits. \\ - Model simulation with stop-loss and excess-of-loss reinsurance arrangements.
}

\section{Article Info}

Received: 19/02/2019

Accepted: 25/11/2019

\section{Keywords}

Stop-loss

Excess-of-loss

Optimal retention

Expected profit

VaR

\begin{abstract}
Many optimal reinsurance studies in the literature only take into consideration the insurer. However, there are two parties in reinsurance contracts. The aim of the study is to contribute to the optimal reinsurance literature by considering the interests of both the insurer and the reinsurer. A reasonable compromise between their interests is desired. Then, we examine the optimal retention problem that minimizes the absolute value of the difference between the insurer's and the reinsurer's profits under stop-loss and excess-of-loss reinsurance arrangements. With a nonnegative random variable, we incorporate the stochastic essence of the aggregate loss for the reinsurer's and insurer's profits into the model. For reinsurance premium calculation we use two different premium principles and for aggregate loss we use exponential, Pareto and lognormal distributions. The results of the studies only deal with the benefits of the insurer and the studies consider both the benefits of the insurer and reinsurer are compared. Our findings can be helpful for insurance companies and reinsurer companies in their decision making task. For simulation studies in the model MATLAB programming language is used.
\end{abstract}

\section{INTRODUCTION}

Reinsurance can be used as a risk management tool that enables the insurance company to share a portion of his risk with the reinsurer. Non-proportional reinsurance (stop-loss and excess of loss) that is of a trete reinsurance type is the most commonly used one of reinsurance contracts. The expected value premium principle is one of the often used premium calculation principles. The other principles are the variance principle, the standard deviation principle and the mean value principle. The well known risk measures and the features are presented and discussed in literature [1-3]. This paper considers Value at Risk (VaR) and Conditional Tail Expectation (CTE) measures. These measure are used in the finance and insurance areas by authors [4-7]. An insurer (cedent) requiring reinsurance protection should make a choice between the amount of reinsurance premium to be paid and the amount of risk it will undertake. The insurer, who wants to have low retained loss, has to pay high reinsurance premium. On the other hand, if he wants to pay less reinsurance premium, he will be faced with a large retained loss. At this point, the optimal retention determining problem is getting important.

Therefore, there are many optimal reinsurance studies in the literature which depend on different reinsurance contracts, premium principles and risk measurements. These papers depend on optimal reinsurance minimize or maximize different measures of the risk. These measures can be expected utility and probability of ruin [8-12] or variance of the retained risk [13]. Borch [14], Denuit and Vermandele [15] and Kaluszka [16] minimize the variance of the retained loss. He, Hou and Liang [17] considered solvency 
constraints in terms of ruin probability in the finite-time case. Centeno and Guerra [18] tried to maximize the adjustment coefficient of the retained risk for the insurer. Gajek and Zagrodny [19] examined the absolute deviation and the truncated variance of the retained loss. Balbas et all. [20] conducted studies on a class of convex principles of premium calculation. Some other measures of the risk that are used in optimal reinsurance studies are the expected time to reach a goal [21], distortion risk measure [22, 23], the liability of an insurer [24], insurer's capital requirement [25], sharpe ratio and mean-variance utility [26], survival probability [19], the expected time to reach a goal [27] etc.

Cai and Tan [28] determined the optimal retention level under stop-loss reinsurance contract and expected value premium principle by using Value at Risk (VaR) and Conditional Tail Expectation (CTE) risk measures. An extended version of this study is written by Tan, Weng and Zhang [29]. Most of the optimal reinsurance studies are from the insurance point of view; see for example; [8,9,11,13-22, 25, 26, 30], with few being from the reinsurance point of view, one such example being the following [31, 32].

We must consider that there are two parties to a reinsurance contract. As Borch states [33], "These considerations should remind us that there are two parties to a reinsurance contract, and that these parties have conflicting interests. The optimal contract must then appear as a reasonable compromise between these interests. To me the most promising line of research seems to be the study of contracts, which in different ways can be said to be optimal from the point of view of both parties." In the actuarial literature we can find some optimal reinsurance studies which have considered a point of view common to the insurer and the reinsurer. The objective function for Ignatov et al. [34] and Kaishev and Dimitrova [35] is the joint survival probability and for Cai et al. [23] is both the joint profitable and the joint survival probability. In the study of Castaner et al. [36] the joint risks of the cedent and the reinsurer are presented. Castaner and Claramunt [37] contribute to the optimal reinsurance literature by considering stop-loss reinsurance from the joint point of view of the cedent and the reinsurer. For further examples see [38-44].

The aim of this study is to play a part in the analysis of the optimal reinsurance from the point of the view of the cedent and the reinsurer by minimizing the absolute value of the difference between the profit of the insurer and the reinsurer. We use excess-of-loss and stop-loss reinsurance contracts. We assume that the non-negative loss random variable $\mathrm{X}$ originally faced by the insurer has a continuous distribution and we use Pareto, lognormal and exponential distributions. We use two different premium principles (standard deviation and expected value) for reinsurance premium. The paper is organized as follows: in section 2, we give some preliminaries on VaR and CTE risk measures and simulation optimization. In section 3 the framework of our simulation model is constructed. In Section 4 numerical results are discussed. The last section concludes the study with the obtained results and some suggestions for further research.

\section{PRELIMINARIES}

\subsection{Value at Risk and Conditional Tail Expectation}

Value at Risk is known as a measure that can reveal the risk status of a financial institution or firm as a whole. This is easier to understand when compared to conventional risk measures, and can be expressed by associating risk amounts with the probability of occurrence of risk. VaR can be used for setting total risk target, determining the allocation of capital within the company, evaluation of different investment options. For more details see [45]. Let $x$ be a non-negative random variable denoting the aggregate loss.

The VaR of $x$ at a confidence level $1-\alpha, 0<\alpha<1$, is defined as

$\operatorname{VaR}_{X}(\alpha)=\inf \{x: P(X>x) \leq \alpha\}$.

A drawback of VaR is that it only makes use of the cut-off point corresponding to the probability level $\alpha$ and does not use any information about the tail distribution beyond this point. The Conditional Tail Expectation corrects for this. The CTE at probability level $\alpha$, denoted by $\operatorname{CTE}_{x}(\alpha)$ is defined as 
$\operatorname{CTE}_{X}(\alpha)=E\left(X \mid X>x_{\alpha}\right)$.

When $\mathrm{X}$ is continuous, the above can be written as

$\operatorname{CTE}_{X}(\alpha)=E\left(X \mid \operatorname{VaR}_{x}(\alpha)\right)$.

\subsection{Simulation Optimization}

Simulation is an analytical approach, especially when the size and complexity of the problem made it difficult or otherwise impossible to use analytical techniques. It can be used for optimizing performance measurements. The general optimization problem that minimizes a given objective function, i.e.,

$\min _{\theta \in \Theta} J(\theta)$

where $\theta \in \Theta$ stands for the input variables, $J(\theta)$ represents the objective function, and $\Theta$ is the constraint set and,

$J(\theta)=E[L(\theta, \varepsilon)]$

is the most common formulation for J. In Equation $5, L(\theta, \varepsilon)$ depicts the sample production estimate obtained from the simulation result and $\varepsilon$ is used for the stochastic effects of the system in the simulation model $[46,47]$. The primary optimization methods that are commonly used in simulation optimization are random search, response surface methodology, sample path optimization, gradient-based procedures, metaheuristics including tabu search, ranking and selection. See [46, 47] and [48] for more detailed information about simulation optimization.

\section{FRAMEWORK OF THE MODEL}

To develop the stochastic model for a non-life insurance company we use both excess of loss and stop-loss reinsurance types. We assume one year time period for total cost and to calculate the optimal retention level we set up the simulation optimization model.

\subsection{Stochastic Reinsurance Simulation Model}

Let $\mathrm{X}$ be the amount of the aggregate loss initially assumed by an insurer. $\mathrm{X}$ is assumed as a non-negative random variable so the stochasticity of aggregate loss is included in the simulation model [28].

In stop-loss reinsurance contract, total loss in one period, $X$, is split between the insurer's part, $X_{I}$, and reinsurer's part that insurer cedes part of its loss, $X_{R}=X-X_{I}$. With $d>0$ retention level $X_{I}=\min \{x, d\}$ represents the losses to the insurer and $X_{R}=\max \{0, x-d\}$ represents the losses to the reinsurer. In the excess-of-loss reinsurance contract, the corresponding losses are $X_{I}=\sum_{i=1}^{N} \min \{x, d\}$, and $X_{R}=\sum_{i=1}^{N} \max \{0, x-d\}$.

In exchange for ceding the risk to the reinsurer, the insurer is facing additional reinsurance premium costs. Therefore, the lower retention limit causes the higher reinsurance premium $\pi(d)$.

We list expected value and standard deviation premium calculation principles as follows:

$$
\pi_{R}(d)=(1+\rho) E\left(X_{R}\right)
$$


$\pi_{R}(d)=E\left(X_{R}\right)+\rho \sqrt{V\left(X_{R}\right)}$.

In equations, $\rho>0$ is the safety loading, $E\left(X_{R}\right)$ is the expected value of $X_{R}$ and $V\left(X_{R}\right)$ is the variance of $X_{R}$. Insurer's total cost for stop-loss reinsurance contract consists of reinsurance premium and retained loss;

$T=X_{I}+\pi_{R}(d)$.

We assume the premium gained by the insurance company is calculated with the same safety loading $\rho$ and we use expected value premium principle; that is, $\pi_{I}=(1+\rho) E(X)$. The profit of the insurer is the difference between the premium gained by the insurance company and the total cost of the insurer:

$S_{I}=\pi_{I}-T$.

Equation 10 represents the profit of the reinsurer and Equation 11 represents the absolute difference between the profit of the insurer and the profit of the reinsurer [49]:

$$
\begin{aligned}
& S_{R}=\pi_{R}-X_{R} \\
& A B S_{\text {Diff }}=\left|S_{I}-S_{R}\right| .
\end{aligned}
$$

\subsection{Simulation Optimization Model}

Our mathematical model is difficult and complex to solve analytically, so we offer effective solutions for calculation of optimal retention level under VaR risk measure by using pattern search solver in MATLAB Optimization Toolbox. From the insurer point of view, let the optimal retention $d^{*}$ is the solution to the "minimization of the VaR of total cost" problem

$\min _{d \in[0, \infty)} E\left[\operatorname{VaR}_{T}(d, \alpha, \varepsilon)\right]$.

Table 1. Distribution parameters for lognormal and Pareto

\begin{tabular}{|c|c|c|c|c|c|}
\hline$\sigma$ & \multicolumn{2}{|c|}{ Lognormal } & \multicolumn{3}{c|}{ Pareto } \\
\cline { 2 - 6 } & $\mu$ & $\sigma$ & shape & scale & location \\
\hline 500 & 6.7962 & 0.4724 & 0.3090 & 213.52 & 690.99 \\
\hline 1000 & 6.5612 & 0.8325 & 0.4142 & 242.64 & 585.78 \\
\hline 1500 & 6.3184 & 1.0856 & 0.4541 & 247.89 & 545.83 \\
\hline 2000 & 6.1030 & 1.2686 & 0.4721 & 249.22 & 527.86 \\
\hline
\end{tabular}

From the joint point of view of the reinsurer and the cedent, the optimal retention is found by minimizing of VaR of the absolute value of the difference between the reinsurer's and the insurer's profits

$\min _{d \in[0, \infty)} E\left[\operatorname{VaR}_{A B S_{D i f}}(d, \alpha, \varepsilon)\right]$.

The retention level for a given confidence level $1-\alpha$ which makes $V a R$ is minimized is the optimal retention level, $d^{*}$. Likewise, objective functions can be written for CTE risk measurement. We assume two different $\alpha$ and $\rho$ pairs $(\alpha=0.10, \rho=0.20$ and $\alpha=0.05, \rho=0.30)$. X has lognormal and Pareto distributions with mean 1000 and standard deviations 500, 1000, 1500 and 2000; exponential distribution with mean and standard deviation 1000. The distribution parameters to be used to provide the above statistics for lognormal and Pareto distributions are given in Table 1. 


\subsection{Simulation results}

Firstly, we observe the results for the stop-loss reinsurance contract for $\alpha=0.10$ and $\rho=0.20$. Table 2 shows the optimal retention values for different standard deviations, premium principles and distributions from joint point of view of the insurer and the reinsurer. For both premium principles, as values of standard deviation increase optimal retention values decrease. For the same premium principles lognormal distribution has the smallest $d^{*}$ values and exponential distribution has the biggest one.

Table 3 shows the optimal retention values for different standard deviations, premium principles and distributions from insurer point of view. From point of view of the insurer as the standard deviation increases optimal retention level decreases and this situation is more distinct for the standard deviation premium principle. As insurer aim to maximize his profit, he tries to minimize the total cost and this situation causes low optimum retention and this is not applicable in real world. However the joint point of view provides a reasonable optimal retention for two sides. The results are obtained with the stochastic optimization in Table 2 and Table 3 are approximate solutions.

Table 2. Optimal retention levels for stop-loss from joint point of view

\begin{tabular}{|l|l|r|r|r|r|}
\cline { 3 - 6 } \multicolumn{2}{c|}{} & \multicolumn{4}{c|}{$\sigma$} \\
\hline \multirow{2}{*}{ Distributions } & Premium principles & \multicolumn{1}{|c|}{$\mathbf{5 0 0}$} & \multicolumn{1}{c|}{$\mathbf{1 0 0 0}$} & $\mathbf{1 5 0 0}$ & \multicolumn{1}{c|}{$\mathbf{1 0 0 0}$} \\
\hline \multirow{2}{*}{ Lognoreto } & Expected value & 1049.80 & 995.94 & 952.06 & 928.00 \\
\cline { 2 - 6 } & Standart deviation & 950.75 & 844.00 & 818.00 & 750.75 \\
\hline \multirow{2}{*}{ Exponential } & Expected value & 965.00 & 950.00 & 780.00 & 692.15 \\
\cline { 2 - 6 } & Standart deviation & 979.92 & 864.03 & 756.00 & 628.00 \\
\cline { 2 - 6 } & Expected value & - & 1004.00 & - & - \\
\cline { 2 - 6 } & Standart deviation & - & 964.00 & - & - \\
\hline
\end{tabular}

Table 3. Optimal retention levels for stop-loss from insurer point of view

\begin{tabular}{|l|l|r|r|r|r|}
\cline { 3 - 6 } \multicolumn{2}{c|}{} & \multicolumn{4}{c|}{$\sigma$} \\
\hline \multirow{2}{*}{ Distributions } & Premium principles & \multicolumn{1}{c|}{$\mathbf{5 0 0}$} & $\mathbf{1 0 0 0}$ & \multicolumn{1}{c|}{$\mathbf{1 5 0 0}$} & \multicolumn{1}{c|}{$\mathbf{2 0 0 0}$} \\
\hline \multirow{2}{*}{ Lareto } & Expected value & 735.25 & 636.75 & 587.93 & 564.00 \\
\cline { 2 - 6 } & Standart deviation & 512.00 & 404.00 & 532.00 & 488.00 \\
\hline \multirow{2}{*}{ Exponential } & Expected value & 572.50 & 308.25 & 182.00 & 115.98 \\
\cline { 2 - 6 } & Standart deviation & 243.81 & 12.50 & 51.5 & 1.99 \\
\cline { 2 - 6 } & Expected value & - & 196.00 & - & - \\
\cline { 2 - 7 } & Standart deviation & - & 4.00 & - & - \\
\hline
\end{tabular}

In terms of distributions, with mean 1000 and standard deviation 1000 is considered in order to make comparisons for all three distributions. When both parties are taken into consideration, the exponential distribution works out the highest optimal retention value; conversely, when only insurance company is taken into consideration, the exponential distribution works out the lowest optimal retention value. This applies for both to the expected value premium principle and to the standard deviation premium principle.

Figure 1 provides pdfs of the three loss distributions with mean and standard deviation of 1000 . For this case, the heaviest tail belongs to the exponential distribution. Value at risk is affected by tails. Where at lower levels of confidence heavy tailed distributions can produce a lower VaR level than other distributions. Therefore, when the loss is exponentially distributed and only insurance company is taken into consideration, the optimal retention level for the insurer seeking to minimize the VaR of its total cost is smaller than other distributions. Table 3 also shows that the optimal retention level decreases as the tail heaviness increases. 


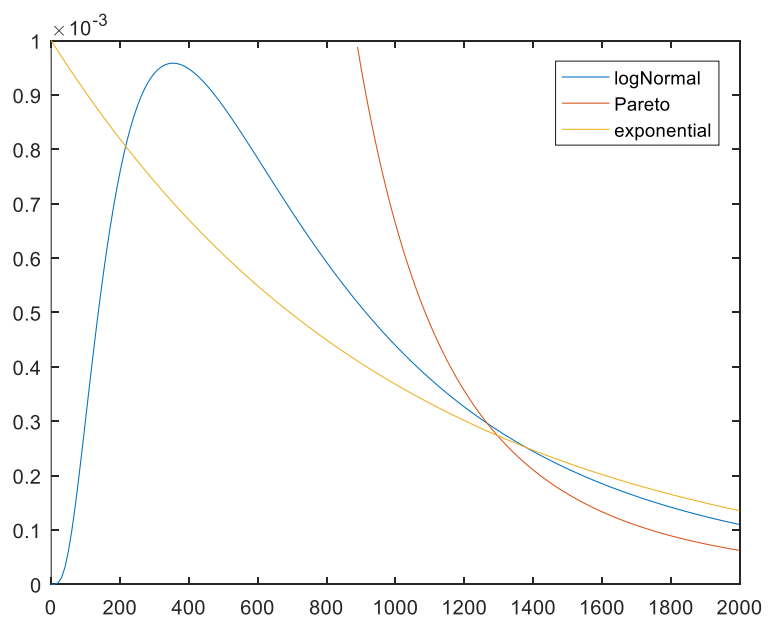

Figure 1. Comparison of distributions

For excess-of-loss insurance contracts we compare the results on figures instead of tables. Figure 2 compares CTE and VaR values in terms of lognormal, Pareto and exponential distributions. In the left column of the figure there are the results obtained using the expected value premium principle and on the right side we have the results obtained using the standard deviation premium principle.
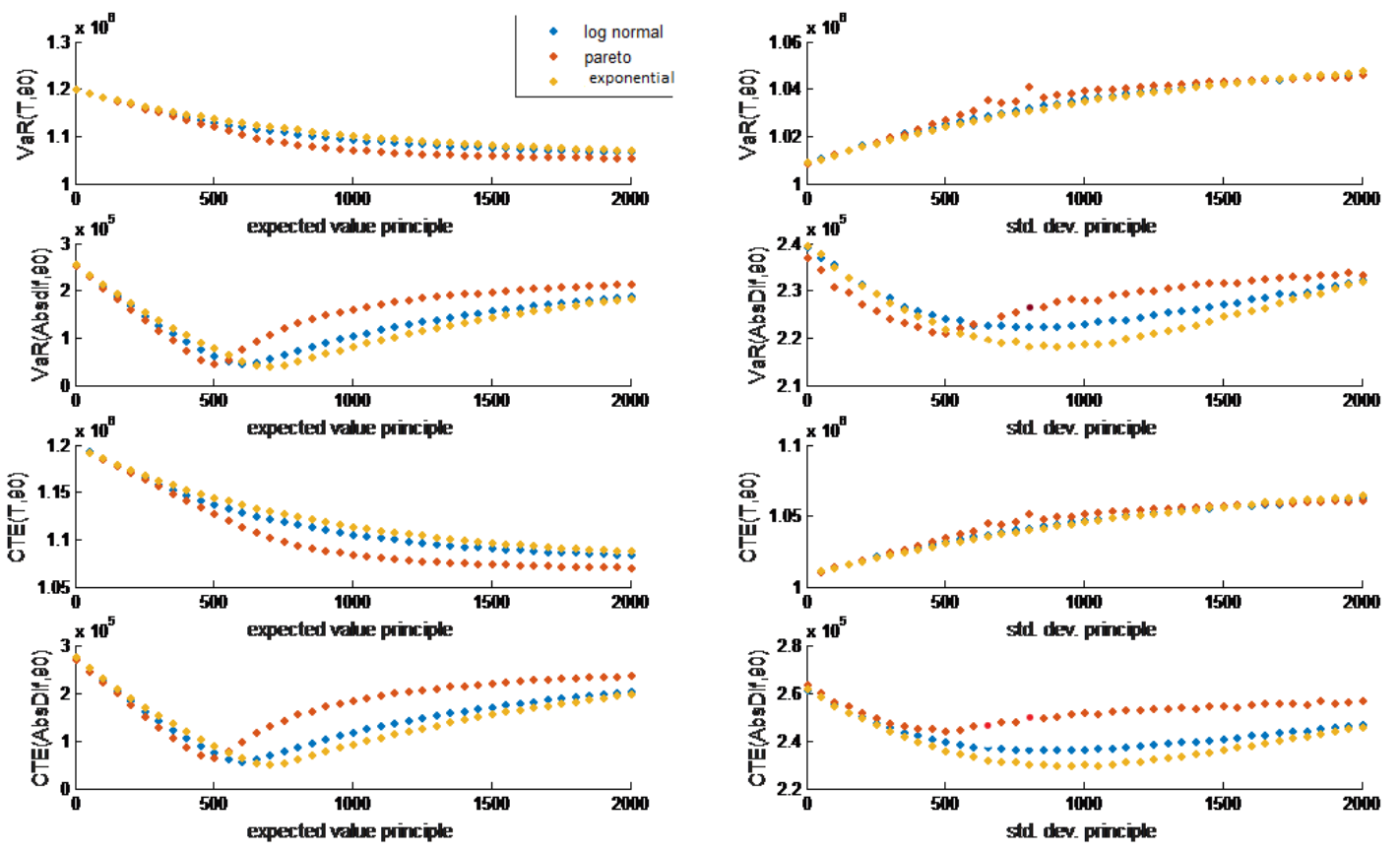

Figure 2. Comparison of distributions for excess-of-loss

In all graphs of Figure 2, on the $\mathrm{x}$ axis there are retention values from 0 to 2000 and on the $\mathrm{y}$ axis we have the VaR and CTE values. T is used for the insurer's point of view and AbsDiff is used for the joint point of view. Taking into account the graphs on the left side we can compare the distributions with respect to the expected value premium principle. In all graphs the VaR and the CTE values for the individual claims which follow lognormal distribution are between the individual claims which follow the Pareto and exponential distributions. From the point of the insurer, the VaR and CTE values are the highest in the case of exponential claims. On the other hand, Pareto claims result in the highest VaR and CTE values after exceeding optimal levels from the joint point of view. As the retention level increases VaR and CTE values decrease from the insurer point of view. 
Comparison of premium principles from joint point of view is displayed in Figure 3. For all distributions and standard deviations it can be clearly seen, the expected value premium principle reaches an optimal retention level which is between 500 and 1000 but close to 500. On the other side we don't have a clear view of the optimal retention level for the standard deviation premium principle although it exists. Comparison of premium principles from insurer's point of view is displayed in Figure 4. If insurer uses the standard deviation premium principle for reinsurer's premium principle he reaches optimum retention level immediately (nearly zero).Therefore, when we consider the situation from the insurer point of view, insurer doesn't want to take risk and want to transfers almost all. Under the expected value premium principle, when standard deviation value approaches the mean value (1000) retention level nearly reaches the optimum level and for the increasing values of standard deviation optimum level moves forward.
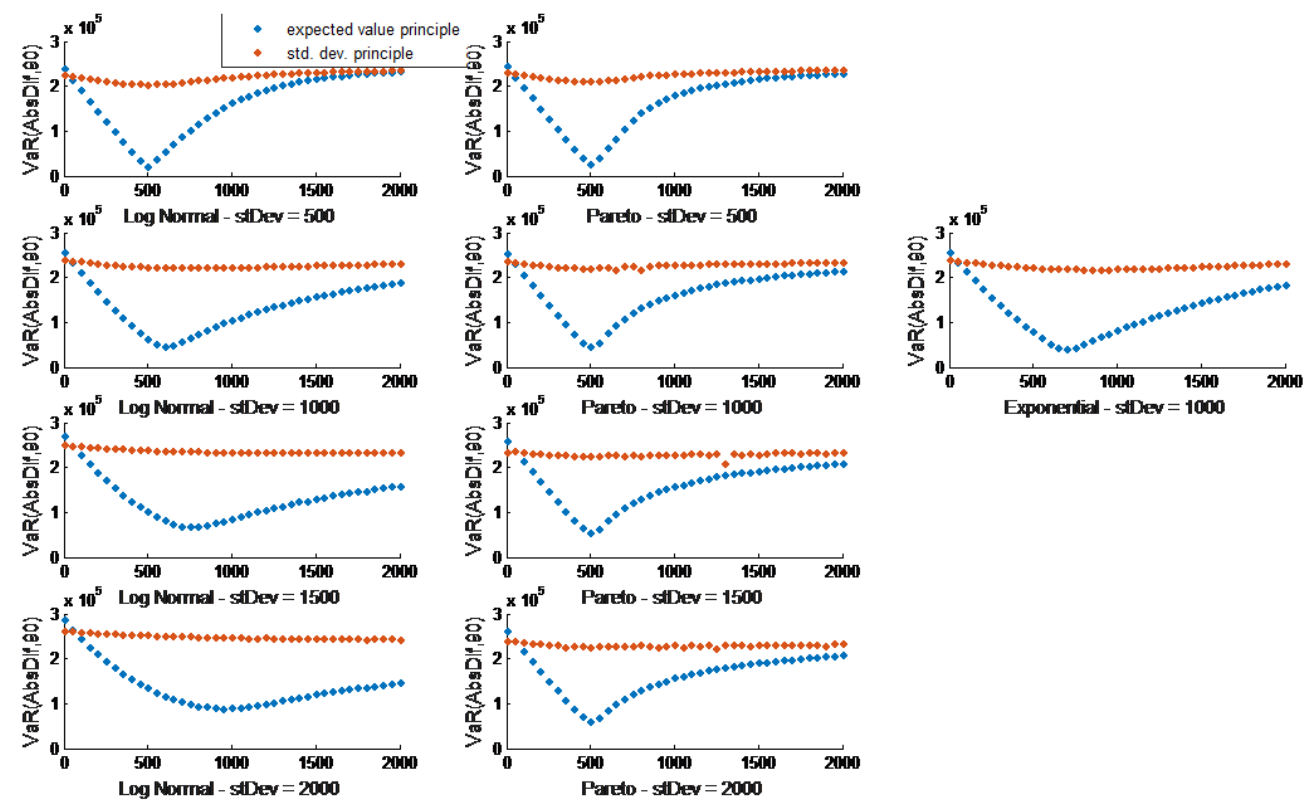

Figure 3. Comparison of premium principles from joint point of view for excess-of-loss
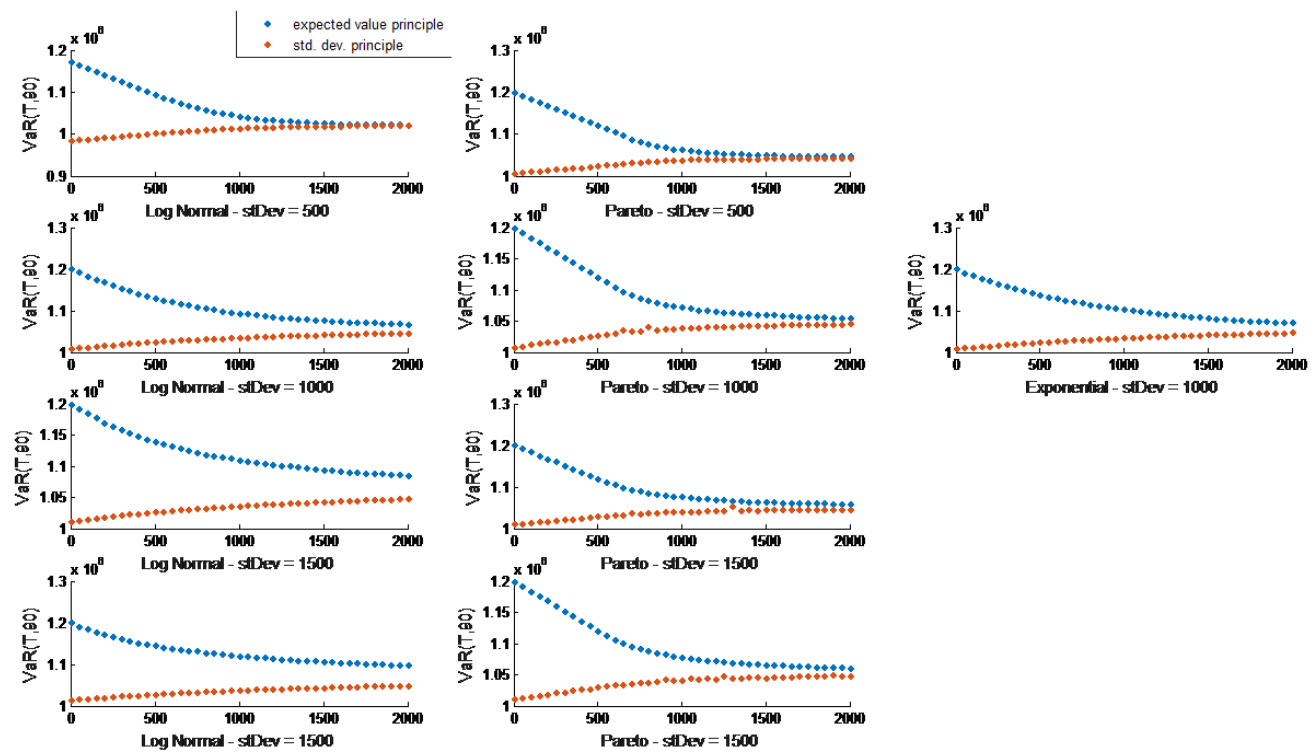

Figure 4. Comparison of premium principles from insurer's point of view for excess-of-loss 
For Figures 5 and $6 \alpha=0.05$ and $\rho=0.30$ pair is used. We use stop-loss reinsurance contract and expected value premium principle. The mean value and the standard deviation are both 1000. In Figure 6, objective functions based on $\mathrm{VaR}$ risk measurement values $\left(V a R_{T}\right.$ and $\left.V a R_{|d i f f|}\right)$ and $d_{T}^{*}$ and $d_{|d i f f|}^{*}$ optimal retention levels, which make these functions minima, are given from one side and from both sides. The $V_{a} R_{T}$ function achieves the minimum where the $V a R_{|d i f f|}$ function reaches its maximum values. Thus if we take a standstill only from insurer's perspective, the most profitable position for one side will be the most unfavorable position for both.
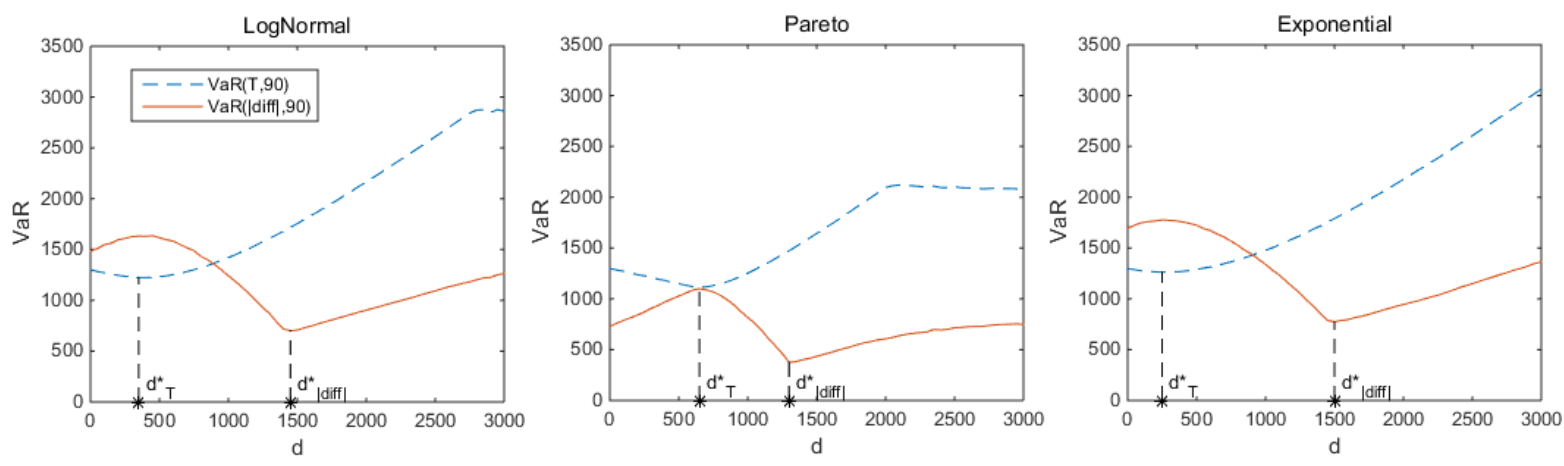

Figure 5. Comparison of VaR levels for Pareto, lognormal and exponential distributions

Table 4 shows the optimal retention values for each of the three distributions and the difference between them is evident. When we consider the benefit of both parties, optimal retention values are much higher than that of a single party. The highest difference is for exponential distribution.

Table 4. Optimal retention levels for lognormal, Pareto and exponential distributions

\begin{tabular}{|l|c|c|}
\hline \multicolumn{1}{|c|}{ Distributions } & $d_{T}^{*}$ & $d_{\mid d i f f}^{*}$ \\
\hline Lognormal & 372 & 1453 \\
\hline Pareto & 644 & 1308 \\
\hline Exponential & 244 & 1476 \\
\hline
\end{tabular}
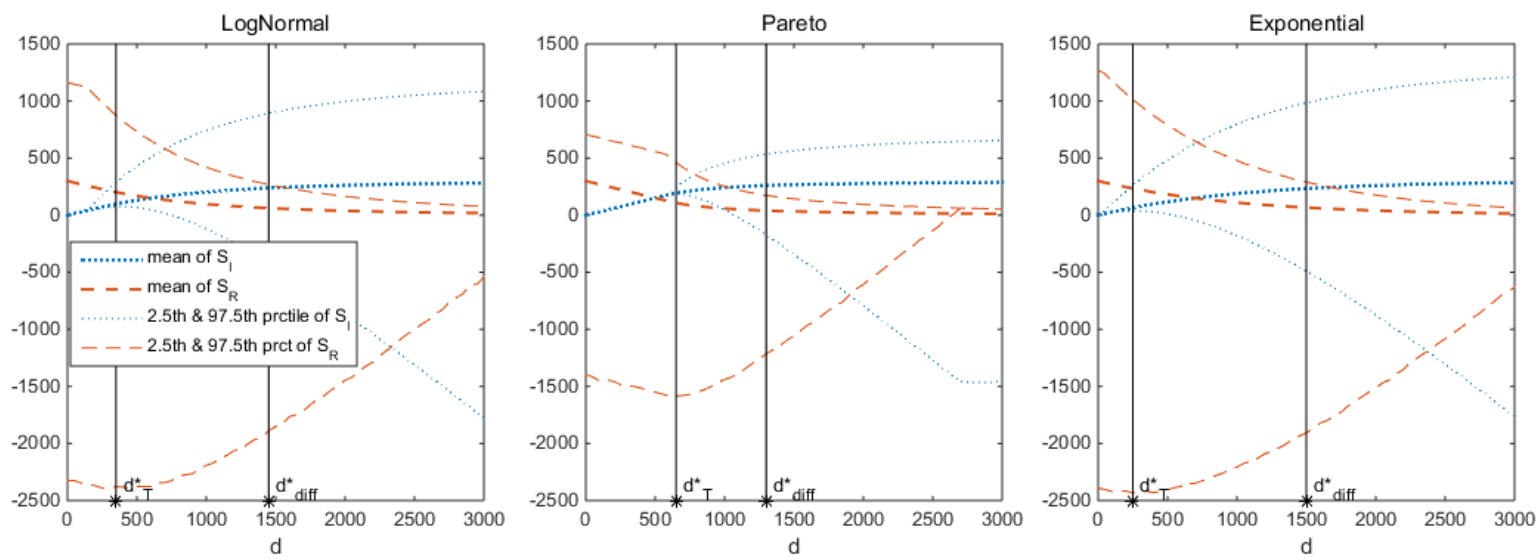

Figure 6. Comparison of optimal retention levels for insurer's and reinsurer's profits

In Figure 6, the comparison is made in terms of profits. Profits and confidence intervals of the insurer and reinsurer are given. When we compare the confidence intervals, the confidence interval of the insurer is very narrow and the confidence interval of the reinsurer is very wide. In this case, the risk for reinsurer is high. At the $d_{|d i f f|}$ level, which is the optimal retention level calculated by taking into account the advantage 
of both sides, the confidence intervals approach each other. For all three distributions the mean value of the insurer's profit increases and the mean value of the reinsurer's profit decreases while retention levels change from $d_{T}^{*}$ to $d_{|d i f f|}^{*}$. This decrease is small and is not an unacceptable because the confidence interval and the risk decrease.

\section{CONCLUDING REMARKS}

In this study, we use the simulation optimization approach to find an answer to the problem of finding the optimal retention level that minimizes the absolute value of the difference between the insurer's and reinsurer's profits in excess-of-loss and stop-loss reinsurance. We compare the results from insurer point of view and joint point of view. We also make the comparison of results in terms of premium principles, loss distributions and profits. Computational results show that, the optimal retention level calculated by only taking into account the insurer is against the reinsurer company. The reinsurance treaties, which have two opposing sides, should take into account both sides and provide an optimal retention level, which is more appropriate to real life and acceptable to also the reinsurer. Another result is that in calculating optimal retention level, assumed premium principle and loss model are impactful factors. In some problems, it is very difficult to reach the optimal solution analytically. In such cases the solution can be obtained by simulation. Consequently, for simulation optimization CTE and VaR risk measures can be used effectively to determine the optimal retention level.

\section{CONFLICTS OF INTEREST}

No conflict of interest was declared by the authors.

\section{REFERENCES}

[1] Artzner, P., Delbaen, F., Eber, J. M., \& Heath, D., "Coherent measures of risk", Mathematical Finance, 9(3): 203-228, (1999).

[2] Kaas, R., Goovaerts, M., Dhaene, J., \& Denuit, M. "Modern actuarial risk theory: using R (Vol. 128)", Springer Science \& Business Media, (2008).

[3] Szegö, G, "Measures of risk”, European Journal of Operational Research, 163(1): 5-19, (2005).

[4] Kara, E. K. and Gebizlioglu, O. L., "Measurement of bivariate risks by the north-south quantile points approach", Journal of Computational and Applied Mathematics, 255: 208-215, (2014)

[5] Kara, E. K. and Kemaloglu, S. A., "Risk Measures of the ERNB Distribution Generated by G-NB Family", Mathematical Sciences and Applications E-Notes, 5(1): 77-84, (2017).

[6] Kemaloglu, S A. and Kizilok Kara, E., "Modeling Dependent Financial Assets by Dynamic Copula and Portfolio Optimization Based on CVaR", Commun. Fac. Sci. Univ. Ank. Series A1, 64(1): 1-13, (2015).

[7] Denuit, M., Dhaene, J., Goovaerts, M., \& Kaas, R., "Actuarial theory for dependent risks: measures, orders and models", John Wiley \& Sons, (2006).

[8] Dickson, D.C.M., and Waters, H.R., "Relative reinsurance retention levels", ASTIN Bull., 27: 207227, (1997).

[9] Dickson, D.C.M., and Waters, H.R., "Optimal dynamic reinsurance”, ASTIN Bull., 36: 415-432, (2006). 
[10] Taksar, M., and Markussen, C., "Optimal dynamic reinsurance policies for large insurance portfolios", Finance and Stochastic, 7: 97-121, (2003).

[11] Hipp, C., and Taksar, M. "Optimal non-proportional reinsurance control”, Insurance: Mathematics and Economics, 47: 246-254, (2010).

[12] Nie, C., Dickson, D.C.M., and Li, S., "Minimising the ruin probability through capital injections", Insurance: Mathematics and Economics, 5: 195-209, (2011).

[13] Van Heerwaarden, A.E., Kaas, R., and Goovaerts, M.J., "Optimal reinsurance in relation to ordering of risks", Insur. Math. Econ., 8(1):11-17, (1989).

[14] Borch, K., "An attempt to determine the optimum amount of stop-loss reinsurance", Transactions of the 16th International Congress of Actuaries, 597-610, 1960.

[15] Denuit, M., Vermandele, C., "Optimal reinsurance and stop-loss order", Insurance: Mathematics and Economics, 22: 229-233, (1998).

[16] Kaluszka, M., "Optimal reinsurance under mean-variance premium principles", Insurance: Mathematics and Economics, 28: 61-67, (2001).

[17] He, L., Hou, P., and Liang, Z., "Optimal control of the insurance company with proportional reinsurance policy under solvency constraints", Insurance: Mathematics and Economics, 43: 474479, (2008).

[18] Centeno, M.L., Guerra, M., "The optimal reinsurance strategy - the individual claim Case", Insurance: Mathematics and Economics, 46: 450-460, (2010).

[19] Gajek, L., and Zagrodny, D., "Optimal reinsurance under general risk measures", Insurance: Mathematics and Economics, 34: 227-240, (2004).

[20] Balbas, A., Balbas, B. And Heras, A., "Optimal reinsurance with general risk measures", Insurance: Mathematics and Economics, 44: 374-384, 2009.

[21] Zeng, X., "Optimal reinsurance with a rescuing procedure”, Insurance: Mathematics and Economics, 46: 397-405, (2010).

[22] Assa, H., "On optimal reinsurance policy with distortion risk measures and premiums." Insur.: Math. Econ, 61: 70-75, (2015).

[23] Cai, J., Fang, Y., Li, Z. And Willmot, G.E., "Optimal reciprocal reinsurance treaties under the joint survival probability and the joint profitable probability", J. Risk Insur, 80(1): 145-168, (2013).

[24] Cai, J., Weng, C. "Optimal reinsurance with expectile”, Scandinavian Actuarial Journal, 7: 624-645, (2016).

[25] Zhu, Y., Chi, Y., and Weng, C., "Multivariate Reinsurance Designs for Minimizing an Insurer's Capital Requirements", Insurance: Mathematics and Economics, 59: 144-155, (2014).

[26] Chi, Y., Zhou, M., "Optimal Reinsurance Design: A Mean-Variance Approach”, North American Actuarial Journal, 21: 1-14, (2017).

[27] Luo, S., Wang, M., and Zeng, X., "Optimal reinsurance: minimize the expected time to reach a goal”, Scandinavian Actuarial Journal, 8: 741-762, (2016). 
[28] Cai, J., Tan, S.K., "Optimal retention for a stop-loss reinsurance under the VaR and CTE risk measures", Astin Bulletin, 37(1): 93-112, (2007).

[29] Tan, K.S., Weng, C., and Zhang, Y., "VaR and CTE criteria for optimal quota-share and stop-loss reinsurance", North American Actuarial Journal, 13(4): 459-482, (2009).

[30] Karageyik, B.B., and Sahin,S, "Optimal retention level for infinite time horizons under MADAM", Risks, 5(1): 1-24 , (2017).

[31] Zhuang, S.C., Boonen, T.J., Tan, K.S., Xu, Z.Q., "Optimal insurance in the presence of reinsurance", Scand. Actuar. J., 6: 535-554, (2017).

[32] Lu, Z., Meng, L., Wang, Y., "Optimal reinsurance under VaR and TVaR risk measures in thepresence of reinsurer's risk limit”, Insurance: Mathematics and Economics, 68: 92-100, (2016).

[33] Borch, K., "The optimum reinsurance treaty", Astin Bull., 5(2): 293-297, 1969.

[34] Ignatov, Z.G., Kaishev, V.K., and Krachunov, R.S., "Optimal retention levels, given the joint survival of cedent and reinsurer", Scand. Actuar. J., 2004(6): 401-430, (2004).

[35] Dimitrova, D.S., Kaishev, V.K., "Excess of loss reinsurance under joint survival optimality", Insurance: Mathematics and Economics, 39(3): 376-389, (2006).

[36] Castaner, A., Claramunt, M., and Lef"evre, C., "Survival probabilities in bivariate risk models, with application to reinsurance", Insur. Math. Econ., 53(3): 632-642, (2013).

[37] Castaner, A., Claramunt, M., “Optimal stop-loss reinsurance: a dependence analysis", Hacet. J. Math. Stat., 2: 497-519, (2016).

[38] Liu, H., Fang, Y., "Optimal quota share and stop loss reinsurance from the perspectives of insurer and reinsurer", J. Appl. Math. Comput., 57(1-2): 85-104, (2018).

[39] Jiang, W.J., Ren, J., Zitikis, R., "Optimal reinsurance policies when the interests of both the cedent and the reinsurer are taken into account", ASTIN Bull. J. Int. Actuar. Assoc., 5(1):1-11, (2016).

[40] Dimitrova, D.S., Kaishev, V.K., "Optimal joint survival reinsurance: An efficient frontier approach", Insur.: Math. Econ., 47: 27-35, (2010).

[41] Bazaz, A. P., Payandeh Najafabadi, A. T., “An Optimal Reinsurance Contract from Insurer's and Reinsurer's Viewpoints”, Applications and Applied Mathematics, 10(2): 970-982, (2015).

[42] D'ortana, N.E., Marcarelli, G. "Optimal proportional reinsurance from the point of view of cedant and the reinsurer", Scandinavian Actuarial Journal, 4: 366-375, (2017).

[43] Cai, J., Lemieux, C., and Liu, F., "Optimal reinsurance from the perspectives of both an insurer and a reinsurer", ASTIN Bulletin, 46: 815-849, (2016).

[44] Hürlimann, W., "Optimal reinsurance revisited—Point of view of cedent and reinsurer", Astin Bull. 41: 547-574, (2011).

[45] Dowd, K. "Value-at-risk. In: Sundt, B. and Teugels, J. (Eds)", Encyclopedia of Actuarial Science New York: John Wiley Sons, Ltd, (2004). 
[46] Glover, M.C.Fu,F.W. and April, J., "Simulation optimization: a review, new developments, and applications. In: Kuhl M.E., Steiger N.M., Joines J.A. (Eds)", Proceedings of the 2005 Winter Simulation Conference, (2005).

[47] Fu, M.C., Chen, C.H., and Shi, L., "Some topics for simulation optimization. In: Mason,S.J., Hill, R. R., Mönch, L., Rose, O., Jefferson, T., and Fowler, J. W. (Eds)", Proceedings of the 2008 Winter Simulation Conference, (2008).

[48] Tekin, E., and Sabuncuoglu, I. "Simulation optimization: A comprehensive review on theory and applications", IIE Transactions, 36:1067-1081, (2004).

[49] Büyükyazıc1, M., "Optimal retention for profit maximizing under VaR levels constraints", Journal of Statisticians: Statistics and Actuarial Sciences, 10: 49-58, (2017). 